\title{
Primary Structures of Three Human Neutrophil Defensins
}

Michael E. Selsted, Sylvia S. L. Harwig, Tomas Ganz, James W. Schilling, and Robert I. Lehrer Department of Medicine, Division of Hematology/Oncology; and Department of Pathology, University of California at Los Angeles School of Medicine, Los Angeles, California 90024; Department of Medicine, Division of Pulmonary Medicine, University of California at Los Angeles School of Medicine, Los Angeles, California 90024; California Biotechnology Inc., Mountain View, California 94043; and Veterans Administration Medical Center, West Los Angeles, California

\begin{abstract}
The primary structures of three human neutrophil antimicrobial peptides (HNP) were determined. The peptides, HNP-1, HNP-2, and HNP-3, which we have termed defensins, were rich in cystine, arginine, and aromatic residues, but were devoid of free sulfhydryl groups and carbohydrate moieties. They were 29-30 residues in length and identical in sequence in all but their amino terminal residues. The defensins were homologous in sequence to peptides of similar size and biological activity previously purified from rabbit polymorphonuclear leukocytes, but unrelated to other neutrophil proteins of known sequence. 11 amino acid residues of the human defensins, including all six cysteinyl residues, were invariantly conserved in the six rabbit members of this multigene peptide family. That similarly structured antimicrobial peptides are present in both rabbit and human leukocytes supports their purported role as cidal agents in phagocyte-mediated host defense.
\end{abstract}

\section{Introduction}

Prominent among the "oxygen-independent" antimicrobial substances isolated from mammalian neutrophils, are a family of low molecular weight cationic peptides exemplified by those recently characterized in rabbit polymorphonuclear leukocytes (PMN). ${ }^{1}$ Six rabbit peptides have been purified to homogeneity and have been found to be active against gram-positive and gramnegative bacteria (1), fungi (2), and herpes simplex virus (3). The peptides were cysteine-rich and arginine-rich, 33-34 residues in length, and within their primary structures, each contained a conserved core of 11 residues (4). The unique structural and functional features of the rabbit peptide family led us to search for peptides of similar size and biological activity in human PMN. Three human neutrophil peptides (HNP), individually named HNP-1, HNP-2, and HNP-3, and collectively termed "defensins," were purified to homogeneity as described (5). The human

This is publication No. 106 of the Collaborative California UniversitiesMycology Research Unit.

Dr. Ganz is a recipient of the Parker B. Francis Fellowship of the Puritan-Bennett Foundation. Address reprint requests to Dr. Selsted, Department of Medicine, Los Angeles, CA 90024.

Received for publication 6 June 1985.

1. Abbreviations used in this paper: HNP, human neutrophil peptides; PITC, phenylisothiocyanate; PMN, polymorphonuclear leukocytes; PTC, phenylthiocarbamyl; PTH, phenylthiohydantoin; RP-HPLC, reversephase high performance liquid chromatography.

J. Clin. Invest.

(c) The American Society for Clinical Investigation, Inc.

$0021-9738 / 85 / 10 / 1436 / 04 \$ 1.00$

Volume 76, October 1985, 1436-1439 defensins exerted prominent antibacterial, antifungal, and antiviral effects in vitro, and were localized immunohistochemically to azurophil granules.

We now report the amino acid sequences of the three human neutrophil defensins. The structures of these peptides were highly conserved and were homologous in sequence to the rabbit neutrophil peptide family.

\section{Methods}

Purification of human defensins. HNP-1, HNP-2, and HNP-3 were purified as recently described (5). Briefly, human blood neutrophils were purified from leukopheresis packs to $>90 \%$ PMN. A granule-rich subcellular fraction was obtained by homogenization and differential centrifugation steps. Granule protein, obtained by acetic acid extraction, was fractionated by gel filtration on a Bio-Gel P-10 column. Homogeneously pure HNP-1, HNP-2, and HNP-3 were obtained by subsequent ion-exchange, gel filtration, and reverse-phase high performance liquid chromatography (RP-HPLC) steps.

$S$-Alkylation of HNP 1-3. Each peptide was reduced and alkylated with iodoacetic acid or iodoacetamide in $6.0 \mathrm{M}$ guanidine hydrochloride, $0.5 \mathrm{M}$ Tris- $\mathrm{HCl}, \mathrm{pH} 8.5,0.2 \mathrm{mM}$ EDTA as previously described (6). The carboxymethyl or carboxamidomethyl peptide derivatives were then desalted by RP-HPLC purification on a $10 \times 250 \mathrm{~mm}$ C-18 column (Vydac;

Table I. Amino Acid Analysis of Human Defensins

\begin{tabular}{|c|c|c|c|}
\hline & HNP-1 & HNP-2 & HNP-3 \\
\hline Arg & $4.14(4)$ & $4.05(4)$ & $4.05(4)$ \\
\hline Asp & $\begin{array}{ll}0 & (0)\end{array}$ & $\begin{array}{ll}0 & (0)\end{array}$ & $1.07(1)$ \\
\hline Thr & $1.12(1)$ & $1.06(1)$ & $1.07(1)$ \\
\hline Glu & 2.04 (1) & $1.90(1)$ & $2.08(1)$ \\
\hline Gln & 0 & $0 \quad$ (1) & $0 \quad$ (1) \\
\hline Pro & $1.02(1)$ & $1.05(1)$ & $1.11(1)$ \\
\hline Gly & $3.02(3)$ & $3.23(3)$ & $2.94(3)$ \\
\hline Ala & $4.02(4)$ & $3.06(3)$ & $3.07(3)$ \\
\hline Cys & $6.01(6)$ & $4.93(6)$ & $5.94(6)$ \\
\hline Ile & $2.67(3)$ & $2.61(3)$ & $2.61(3)$ \\
\hline Leu & $1.14(1)$ & $1.09(1)$ & $1.08(1)$ \\
\hline Tyr & $2.88(3)$ & $2.88(3)$ & $2.87(3)$ \\
\hline Phe & $1.16(1)$ & $1.16(1)$ & $1.10(1)$ \\
\hline Trp & $1.13(1)$ & $1.08(1)$ & $1.06(1)$ \\
\hline Total & (30) & (29) & (30) \\
\hline
\end{tabular}

Representative amino acid analyses of HNP-1, HNP-2, and HNP-3. Compositions were determined after $24 \mathrm{~h}$ hydrolysis of 50-75 pmol of each carboxymethylated peptide. Hydrolysates were analyzed as PTC derivatives. Tryptophan content was determined spectrophotometrically in $6.0 \mathrm{M}$ guanidine hydrochloride, $20 \mathrm{mM}$ sodium phosphate, pH 6.55. Cysteine was determined as $S$-carboxymethylcysteine. Values in parentheses are residue values obtained by sequence analysis. 
The Separations Group, Hesperia, CA), using a water-acetonitrile gradient in which $0.1 \%$ trifluoroacetic acid was present as the ion-pairing agent. Salt-free, reduced and alkylated peptide, obtained by lyophilization in an evaporator (Speed-Vac; Savant Instruments, Inc., Hicksville, NY), was used for all subsequent chemical analyses.

Composition analysis. 50-75 $\mu \mathrm{g}$ of carboxymethylated HNP was hydrolyzed in vacuo in $5.7 \mathrm{~N} \mathrm{HCl} \mathrm{employing} \mathrm{the} \mathrm{micro} \mathrm{method} \mathrm{described}$ by Bidlingmeyer et al. (7). Amino acids were quantitated as phenylthiocarbamyl (PTC) derivatives (8) on a 510 binary HPLC system (MilliporeWaters, Milford, MA) using a Nova-Pak C-18 column (Millipore-Waters) (7). Tryptophan was quantitated spectrophotometrically by the method of Edelhoch (9). For detection of free sulfhydryls, native peptide was titrated with 5,5'-dithiobis (2-nitrobenzoate) (10). Peptide carbohydrate content was estimated by the phenol-sulfuric acid assay (11).

Proteolytic digestion. Reduced and alkylated peptide was digested in $0.1 \mathrm{M} \mathrm{N}$-ethylmorpholine acetate, $\mathrm{pH} 8.20$, with $1.0 \%$ (wt/wt) trypsin, chymotrypsin (Worthington Biochemical Corp., Freehold, NJ), or Staphylococcus aureus V protease (Pierce Chemical Co., Rockford, IL). Digestion was carried out for $2.0 \mathrm{~h}$ (chymotrypsin), $5.0 \mathrm{~h}$ (trypsin), or

Table II. Gas Phase Edman Degradation of Human Defensins

\begin{tabular}{|c|c|c|c|c|c|c|}
\hline \multirow[b]{2}{*}{ Cycle no. } & \multicolumn{2}{|l|}{ HNP-1 } & \multicolumn{2}{|l|}{ HNP-2 } & \multicolumn{2}{|l|}{ HNP-3 } \\
\hline & PTH-AA & Yield* & PTH-AA & Yield & PTH-AA & Yield \\
\hline 1 & Ala & 2,100 & Cys & 1,800 & Asp & 1,070 \\
\hline 2 & Cys & 1,650 & Tyr & 1,620 & Cys & 940 \\
\hline 3 & Tyr & 1,260 & Cys & 1,420 & Tyr & 530 \\
\hline 4 & Cys & 1,200 & Arg & 1,290 & Cys & 860 \\
\hline 5 & Arg & 360 & Ile & 1,850 & Arg & 660 \\
\hline 6 & Ile & 1,340 & Pro & 1,590 & Ile & 1,680 \\
\hline 7 & Pro & 640 & Ala & 2,030 & Pro & 1,300 \\
\hline 8 & Ala & 1,320 & Cys & 1,220 & Ala & 1,400 \\
\hline 9 & Cys & 840 & Ile & 1,550 & Cys & 1,070 \\
\hline 10 & Ile & 480 & Ala & 1,470 & Ile & 950 \\
\hline 11 & Ala & 1,070 & Gly & 1,870 & Ala & 840 \\
\hline 12 & Gly & 850 & Glu & 1,040 & Gly & 890 \\
\hline 13 & Glu & 170 & Arg & 920 & Glu & 430 \\
\hline 14 & Arg & 250 & Arg & 670 & Arg & 370 \\
\hline 15 & Arg & 240 & Tyr & 990 & Arg & 280 \\
\hline 16 & Tyr & 190 & Gly & 1,090 & Tyr & 530 \\
\hline 17 & Gly & 300 & Thr & 560 & Gly & 460 \\
\hline 18 & Thr & 590 & Cys & 450 & Thr & 130 \\
\hline 19 & Cys & 360 & Ile & 620 & Cys & 280 \\
\hline 20 & Ile & 530 & Tyr & 620 & Ile & 400 \\
\hline 21 & Tyr & 100 & Gln & 700 & Tyr & 350 \\
\hline 22 & Gln & 90 & Gly & 680 & Gln & 350 \\
\hline 23 & Gly & 100 & Arg & 420 & Gly & 380 \\
\hline 24 & Arg & 110 & Leu & 540 & Arg & 170 \\
\hline 25 & Leu & 110 & $\operatorname{Trp}$ & 40 & Leu & 270 \\
\hline 26 & Trp & 10 & Ala & 420 & $\operatorname{Trp}$ & 40 \\
\hline 27 & Ala & 160 & Phe & 410 & Ala & 250 \\
\hline 28 & Phe & 310 & Cys & 180 & Phe & 210 \\
\hline 29 & Cys & 120 & Cys & 70 & Cys & 110 \\
\hline 30 & Cys & 80 & - & 0 & Cys & 70 \\
\hline 31 & - & 0 & - & 0 & - & 0 \\
\hline
\end{tabular}

Gas phase Edman degradation of HNP 1-3. 20 nmol of each carboxamidomethylated sample was loaded on a 470 A sequencer (Applied Biosystems, Inc.).

* Yield is expressed as picomoles of identified PTH-amino acid per degradation step.
$18 \mathrm{~h}$ (S. aureus $\mathrm{V}$ protease) at $37^{\circ} \mathrm{C}$. Digestion products were purified by RP-HPLC on a $4.6 \times 250 \mathrm{~mm}$ Vydac $300 \AA \mathrm{C}-18$ column as previously described (6). Purified fragments were hydrolyzed and subjected to amino acid analysis as described above.

Sequence determination. 10-20 nmol of S-carboxamidomethylated HNP-1, HNP-2, and HNP-3 were subjected to gas-phase Edman degradation on an Applied Biosystems, Inc. (Foster City, CA) instrument, essentially as described in reference 12 . Phenylthiohydantoin (PTH) amino acids were identified by RP-HPLC on a Zorbax cyanopropyl column $(5 \mu \mathrm{m}, 4.5 \times 250 \mathrm{~mm})$ as previously described (6).

The carboxyl terminal segment of each defensin was identified and characterized by the tritium-label method of Matsuo and Narita (13). Briefly, each defensin was labeled with tritium at its carboxyl terminus and then digested with trypsin. The digestion fragments were purified by RP-HPLC, and the tritium-containing fragments were characterized by amino acid analysis (6). Carboxypeptidase $Y$ digestion of each peptide was performed as described in reference 14. Briefly, samples of each carboxymethylated HNP were digested with $1.0 \%$ (wt/wt) carboxypeptidase $\mathrm{Y}$ in $0.1 \mathrm{M}$ pyridine-acetate, $\mathrm{pH} 6.35$, for $1,2,4,6$, or $10 \mathrm{~min}$ at $37^{\circ} \mathrm{C}$. Samples were snap-frozen, lyophilized, and derivatized with PITC for amino acid analysis. Samples of the derivatized digest were injected onto the C-18 amino acid column without prior fractionation.

\section{Results}

The chemical compositions of the three defensins were nearly identical (Table I). Each contained six half-cystine and four arginine residues, as well as an abundance of $\mathrm{A}_{280}$ absorbing aromatic residues. The single tryptophan and three tyrosine residues contained in each peptide were consonant with the high extinction coefficients of the defensins: in $0.1 \%$ acetic acid, the $\mathrm{A}_{280}{ }^{1 \%}$ for HNP-1 and HNP-3 was 30.3, and for HNP-2 was 31.3. None of the peptides contained detectable carbohydrate. 5,5'-dithiobis(2-nitrobenzoate) did not react with native HNP1, HNP-2, or HNP-3, indicating the absence of free sulfhydryl
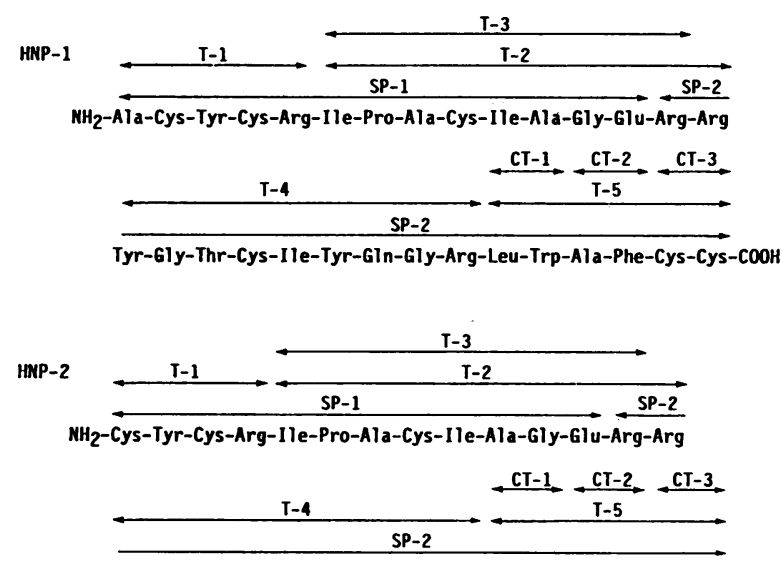

Tyr-6ly-Thr-Cys-Ile-Tyr-GIn-Gly-Arg-Leu-Trp-Ala-Phe-Cys-Cys-COOH (29)

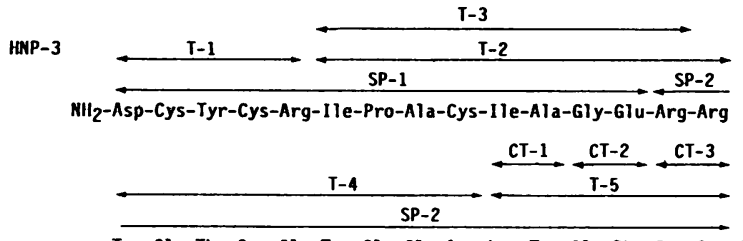

Tyr-Gly-Thr-Cys-Ile-Tyr-GIn-Gly-Arg-Leu-Trp-Ala-Phe-Cys-Cys-COOH

Figure 1. Sequences of human defensins. Arrows designate tryptic (T), chymotryptic (CT), or $S$. aureus V protease (SP) fragments. See text for details of residue assignment. 


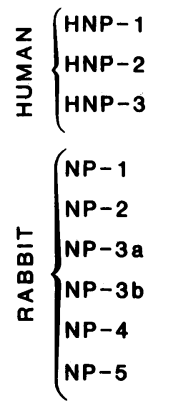
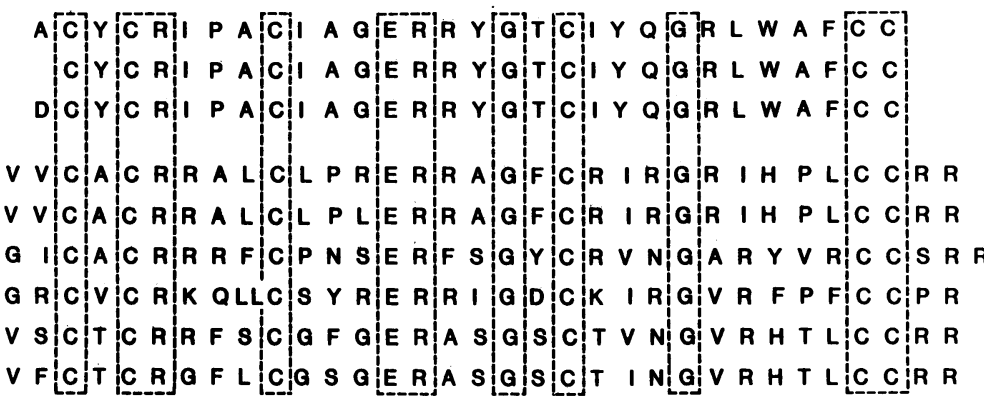

Figure 2. Sequence comparison of human and rabbit defensins. Each sequence is represented by the single-letter amino acid symbol. The sequences were maximally aligned to show the structural homology conferred by the 11 residues common to both the human and rabbit peptides (enclosed in boxes). $A$, alanine; $R$, arginine; $N$, asparagine; $\mathrm{D}$, aspartic acid; C, cysteine; $\mathrm{Q}$, glutamine; E, glutamic acid; G, glycine; $H$, histidine; I, isoleucine; L, leucine; $\mathrm{K}$, lysine; $F$, phenylalanine; $P$, proline; $S$, serine; $\mathrm{T}$, threonine; $\mathrm{W}$, tryptophan; $\mathrm{Y}$, tyrosine; $\mathrm{V}$, valine. groups, suggesting that the six half-cystine residues of each peptide existed as three intramolecular disulfides.

The primary structures of the defensins were determined by automated Edman degradation and confirmed by characterization of purified proteolytic digestion fragments. As shown in Table II, phenylthiohydantoin (PTH)-amino acid residues from 29 (HNP-2) or 30 (HNP-1 and HNP-3) sequencing cycles were identified. The final residue obtained in each of the sequencing runs was determined to be the actual carboxyl terminal residue by ( $a$ ) amino acid analysis of the tryptic fragments generated by digestion of carboxyl terminal tritium-labeled HNP, and $(b)$ by the appearance of $S$-carboxymethylcysteine as the first residue released by carboxypeptidase $\mathrm{Y}$ degradation (data not shown). The sequences of the defensins, shown in Fig. 1, contained four trypsin sites (four arginines), and one $S$. aureus $\mathrm{V}$ protease site (glutamic acid). The single tryptic fragment not containing arginine (T-5) was necessarily the carboxyl terminal fragment and this fragment contained the great majority of tritium counts. The sequences of the carboxyl terminal regions were further confirmed by characterizing the purified chymotryptic peptides (CT-1, CT-2, and CT-3) generated by digestion of tryptic peptide T-5. As demonstrated in Fig. 1, the sequences of the three defensins were identical in all but their amino terminal residues.

The primary structures of the human defensins and the previously characterized rabbit PMN peptides were compared as shown in Fig. 2. Whereas the rabbit peptides each contain 33 or 34 amino acid residues, the human peptides contain 29 or 30 . Both the human and rabbit peptides are uniformly rich in cysteine ( 6 residues/molecule). The rabbit peptides vary in their arginine content from $5(\mathrm{NP}-5)^{2}$ to 10 (NP-1) residues/molecule; the human defensins each contain 4 arginine residues/molecule. With the exception of NP-3b, neither the rabbit nor human peptides contain lysine. At $\mathrm{pH} 7.0$, the rabbit peptides vary in their net charge per molecule [(arginine + lysine) - (glutamic acid + aspartic acid)] from +4 (NP-5) to +9 (NP-1). The defensins have a net charge of +2 (HNP-3) or +3 (HNP-1 and HNP2 ). The presence of three tyrosines and one tryptophan in each defensin molecule contrasts with the virtual absence of these residues from the rabbit peptides.

When aligned as in Fig. 2, the six rabbit and three human PMN peptides showed complete conservation of 11 residues, including all six cysteinyl residues. The absence of free-sulfhydryl

2. Since first our initial report of the rabbit peptide sequences, we have concluded that NP-5 contains 33 residues (compared with 32 originally reported). The carboxyl terminal arginine shown in Fig. 2 was incorrectly omitted in the original determinations. groups in both the rabbit and human peptides indicates that each peptide contains three structure-conferring disulfide bridges. Assignment of the cysteine pairs requires further study.

\section{Discussion}

HNP 1-3 and NP 1-5 are major gene products of human and rabbit PMNs. Whereas several larger (14-60 kD) bactericidal proteins have been isolated from human PMN granules (15), the existence of low molecular weight human antibiotic peptides homologous to those previously shown in rabbit PMN has not previously been described. Perhaps one reason that the human homologs have gone undetected is that attention has been focused on the cationicity of some of these peptides, as evidenced by the designation of the rabbit PMN peptides as "lysosomal cationic proteins" (15). While the defensins each possess a net positive charge at $\mathrm{pH} 7.0$, their electrophoretic migration in low $\mathrm{pH}$ polyacrylamide gel electrophoresis is less cathodal than lysozyme (5), which possesses a computed net charge of +8 (16).

Our sequence data suggests that although certain arginine residues may be of primary consequence, it is the cystine infrastructure, and by inference the molecular conformation, that appears essential for biological activity. The expression and perpetuation of homologous antibiotic peptides in granulocytes of two evolutionarily distinct species is consistent with the possibility that such antimicrobial peptides play a significant role in granulocyte function.

\section{Acknowledgments}

We thank Mrs. Lois F. Howard and Mrs. Deborah G. Todhunter for their excellent assistance in preparing this manuscript.

This work was sponsored in part by contract PB 830501 from Biotechnology Research Partners, Ltd., Palo Alto, CA; and by grant AI 16252 from the National Institutes of Health.

\section{References}

1. Selsted, M. E., D. Szklarek, and R. I. Lehrer. 1984. Purification and antibacterial activity of antimicrobial peptides of rabbit granulocytes. Infect. Immun. 45:150-154.

2. Lehrer, R. I., D. Szklarek, T. Ganz, and M. E. Selsted. 1985. Correlation of binding of rabbit granulocyte peptides to Candida albicans with candidacidal activity. Infect. Immun. 49:207-211.

3. Lehrer, R. I., K. Daher, T. Ganz, and M. E. Selsted. 1985. Direct inactivation of viruses by MCP-1 and MCP-2, natural peptide antibiotics from rabbit leukocytes. J. Virol. 54:467-472. 
4. Selsted, M. E., D. M. Brown, R. J. DeLange, S. S. L. Harwig, and R. I. Lehrer. 1985. Primary structures of six antimicrobial peptides of rabbit peritoneal neutrophils. J. Biol. Chem. 260:4579-4584.

5. Ganz, T., M. E. Selsted, S. S. L. Harwig, D. Szklarek, K. Daher, and R. I. Lehrer. Defensins. Natural peptide antibiotics of human neutrophils. J. Clin. Invest. 76:1427-1435.

6. Selsted, M. E., D. M. Brown, R. J. DeLange, and R. I. Lehrer. 1983. Primary structures of MCP-1 and MCP-2, natural peptide antibiotics of rabbit lung macrophages. J. Biol. Chem. 258:14485-14489.

7. Bidlingmeyer, B. A., S. A. Cohen, and T. L. Tarvin. 1984. Rapid analysis of amino acids using pre-column derivatization. J. Chromatogr. 336:93-104.

8. Heinrikson, R. L., and S. C. Meredith. 1984. Amino acid analysis of reverse-phase high-performance liquid chromatography: precolumn derivitization with phenylisothiocyanate. Anal. Biochem. 136:65-74.

9. Edelhoch, H. 1967. Spectroscopic determination of tryptophan and tyrosine in proteins. Biochemistry. 6:1948-1954.

10. Glazer, A. M., R. J. DeLange, and D. S. Sigman. 1975. Modification of protein side-chains: group-specific reagents. In Chemical
Modification of Proteins. T. S. Work and E. Work, editors. Elsevier/ North Holland, Amsterdam. 113-114.

11. Dubois, M., K. A. Gilles, J. K. Hamilton, P. A. Rebers, and F. Smith. 1956. Colorimetric method for determination of sugars and related substances. Anal. Chem. 28:350-356.

12. Hunkapiller, M. W., R. M. Hewick, W. J. Dreyer, and L. E. Hood. 1983. High-sensitivity sequencing with a gas-phase sequenator. Methods Enzymol. 91:399-413.

13. Matsuo, H., and K. Narita. 1975. Improved tritium-labeling for quantitative C-terminal analysis. In Protein Sequence Determination. S. B. Needleman, editor. Springer-Verlag, Berlin. 104-113.

14. Allen, G. 1981. Preliminary characterization of the protein. In Sequencing of Proteins and Peptides. T. S. Work and R. H. Burdon, editors. Elsevier/North Holland, Amsterdam. 41-42.

15. Elsbach, P., and J. Weiss. 1983. Reevaluation of the roles of the $\mathrm{O}_{2}$-dependent and $\mathrm{O}_{2}$-independent microbicidal systems of phagocytes. Rev. Infect. Dis. 5:843-853.

16. Canfield, R. E., J. C. Collins, and J. H. Sobel. 1974. Human leukemia lysozyme. In Lysozyme. E. F. Osserman, R. E. Canfield, and S. Beychok, editors. Academic Press Inc., New York. 63-70. 